\title{
ALGUNAS CONSIDERACIONES SOBRE EL DISCURSO INDIRECTO EN EL BELLUM GALLICUM DE C. IULIUS CAESAR
}

\author{
Xinia Quirós Robinson.
}

\begin{abstract}
Indirect discourse is a stylistic resource widely used by Latin prose wirters, mainly historiographers, in order to smoothly incorporate the thoughts and speech of others into the narrative without breaking the unit of style. The use of indirect discourse in narrative writing theoretically implies the strict observance of the consecutio temporum rules because it depends automatically on the tense of the main verb, as this type of discourse in turn depends on a tacit or explicit verb. Historians such as Julius Caesar, however, deviate from the consecutio temporum rules and often express themselves freely, using present and perfect tenses that depend on past or imperfect ones, as well as pluperfect tenses dominated by the present. This is a study of such transgressions, as well as those arising from the use of the hypothetic aspect in indirect discourse in Julius Caesar's Bellum Gallicum.
\end{abstract}

La lengua literaria latina usó ampliamente el discurso indirecto, sobre todo la historiografía, ya que este recurso estilístico permitía a los historiadores no sólo dotar a la narración de carácter objetivo, sino también mantener la unidad del estilo, pese a la incorporación, dentro de la obra, de pensamientos y discursos ajenos.

El estilo indirecto depende de verbos llamados de lengua (verba dicendi) o de entendimiento (verba sentiendi). En César son frecuentes los siguientes o perífrasis verbales: egit, respondit, locutus est, facir verba, fuit oratio, exitus fuit orationis, dicunt, veniunt oratum ut, etc. Sin embargo, el escritor puede pasar bruscamente del estilo directo al indirecto prescindiendo por completo del verbo regente, pues, en latín, el discurso indirecto posee características sintácticas y morfológicas tan peculiares que lo hacen reconoscible a simple vista, sin que la presencia de aquel verbo rector sea estrictamente necesaria. Estas elipsis verbales son particularmente frecuentes con verbos que significan "pedir, rogar, aconsejar", cuando el discurso indirecto está precedido por una negación, etc. Basten, al respecto, los siguientes ejemplos:

Ea re impetrata sese omnes flentes Caesari ad pedes proiecerunt: Non minus se id contendere et laborare...(1).
Diuiciacus multis cum lacrimis Caesarem conplexus obsecrare coepit ne quid grauius in fratrem statueret: Scire se illa esse uera...(2).

His responsis ad Caesarem relatis iterum ad eum Caesar legatos cun his mandatis mittit: Quoniam tanto suo populique romani beneficio adfectus... haec esse quae ab eo postularet...(3).

En el primer ejemplo, el contexto nos indica que se ha elidido una forma verbal correspondiente a "rogauerunt", "implorauerunt", etc.; en el segundo, el discurso indirecto está precedido por una negación (ne quid); en el tercero se sobreentiende el verbo "dixerunt" u otro similar.

Usualmente, las oraciones principales se convierten, dentro del estilo indirecto latino, en oraciones de infinitivo y las subordinadas adoptan el modo subjuntivo. Pero, como el verbo regente está casi siempre en pasado, los verbos conjugados que en él aparezcan deben corresponder, según las reglas de la consecutio temporum, a la secuencia del pasado: imperfecto o pluscuamperfecto, si la acción es contemporánea o anterior, respectivamente, a ese pasado; si la acción es posterior se usa el imperfecto de la conjugación perifrástica. Si el verbo regente es un presente o futuro, la consecutio temporum indica que hay que usar el presente, en la oración subordinada, si la acción es con- 
temporánea, el pretérito perfecto, si la acción es anterior, y el presente de la conjugación perifrástica, si la acción es posterior.

El estilo indirecto ciceroniano se convirtió en el modelo en cuanto al uso riguroso de las reglas de la consecutio. Los historiadores, sin embargo, se apartan de ese uso ciceroniano por el empleo frecuente de presentes y perfectos dependiendo de verbos de pasado, ya que este procedimiento, como también el presente histórico, permite traer a la esfera del presente hechos del pasado. Además, es también una manera de romper la uniformidad y monotonía que presenta la interminable sucesión de tiempos de pasado y reproduce, con más exactitud, los tiempos utilizados en el discurso directo. En César suele haber transgresiones de esta índole: ejemplo de esto son los siguientes párrafos:

Locutus est pro his Diuiciacus Haeduus: (...) Unum se esse ex omni ciuitate Haeduorum qui adduci non potuerit ut iuraret... Ariouistum autem, ut semel Gallorum copias proelio uicerit, quod proelium factum sit Admagetobrigae, superbe et crudeliter imperare... (4).

Ariouistus ad postulata Caesaris pauca respondit, de suis uirtutibus multa praedicauit: (...) stipendium capere iure belli, quod uictores uictis inponere consuerint... Quod multitudinem Germanorum in Galliam traducat, id se sui muniendi, non Galliae inpugnandae causa facere; eius rei testimonium esse, quod nisi rogatus non uenerit, et quod bellum non intulerit, sed defenderit.... Quid sibi uellet cur in suas possessiones venerit? ... Debere se suspicari simulata Caesarem amicitia, quod exercitum in Gallia habeat, sui opprimendi causa habere (5).

Apud quos Ambiorix ad hunc modum locutus est: (...) neque id quod fecerit de oppugnatione castrorum aut iudicio aut uoluntate sua fecisse... Ciuitati porro hanc fuisse belli causam, quod repentinae Gallorum coniurationi resistere non potuerit. Id se facile ex humilitate sua probare posse, quod non adeo sit imperitus rerum ut suis copiis populum romanum superari posse confidat.... Quibus quoniam pro pietate satisfecerit, habere nunc se rationem offici pro beneficiis Caesaris: monere, orare Titurium pro hospitio ut suae ac militum saluti consulat (6).

Los ejemplos anteriores corresponden a fragmentos de discursos indirectos, que dependen todos de una forma verbal en pasado: locutus est, praedicauit y locutus est, respectivamente. Las transgresiones de César son evidentes por el insistente uso de presentes y perfectos, en lugar de los imperfectos y pluscuamperfectos correspondientes.

A la inversa, el Bellum Gallicum posee pasajes en los que el discurso indirecto está construido con formas verbales en imperfecto o pluscuamperfecto, a pesar de que el verbo regente es un presente; prueba de ello son los siguientes trozos:

Pro his Diuiciacus... facit verba: (...) inpulsos a suis principibus, qui dicerent Haeduos a Caesare in seruitutem redactos omnes indignitates contumeliasque perferre, et ab Haeduis defecisse et populo romano bellum intulisse. Qui eius consilii principes fuissent, quod intellegerent quantam calamitatem ciuitati intulissent, in Britanniam profugisse (7).

En cuanto al período hipotético, los recursos para construirlo en el discurso indirecto son muy limitados. En el estilo directo se distingue la realidad, posibilidad e irrealidad mediante el uso de diversos tiempos y diversos modos; en el indirecto, en cambio, sólo existe, para la prótasis, la viabilidad de usar el subjuntivo, de tal manera que todos aquellos matices del directo se pierden al hacer la conversión. Sin embargo, se pueden tomar como modelo las siguientes reglas:

apódosis

prótasis

1. condicionales reales:

a. infinitivo de presente o presente o perfecto de subjuntivo pasado

(si el verbo regente está en pasado, la prótasis debe llevar un imperfecto o pluscuamperfecto de subjuntivo)

b. infinitivo de futuro presente o perfecto de subjuntivo

(si el verbo regente está en pasado, la prótasis debe llevar un imperfecto o pluscuamperfecto de subjuntivo)

2. condicional potencial: infinitivo de presente o imperfecto o pluscuamperfecto de futuro

(-urum esse) subjuntivo, según la consecutio temporum

3. condicional irreal:

a. presente perifrástico en-urum imperfecto de subjuntivo fuisse (aún cuando el verbo regente sea un presente)

b. pasado perifrástica en -urum pluscuamperfecto de subjuntivo fuisse 
Sin embargo, las transgresiones de César a estas reglas son frecuentes; los siguientes ejemplos son prueba de ello.

His Caesar ita repondit: (...) Cum ea ita sit, tamen si obsides ab iis sibi dentur, uti ea quae polliceantur facturos intellegat, et si Haeduis de iniuriis quas ipsis sociisque eorum intulerint, item si Allobrogibus satis faciant, sese cum iis pacem esse facturum. (8).

Locutus est pro his Diuiciacus Haeduus: (...) obsides nobilissimi cuiusque liberos poscere et in eos omnia exempla cruciatusque edere, si qua res non ad nutum aut ad uoluntatem eius facta sit. (...) Nisi si quid in Caesare populoque romano sit auxilii omnibus Gallis idem esse faciendum quod Heluetii fecerint, ut domo emigrent, aliud domicilium, alias sedes, remotas a Germanis, petant fortunamque, quaecumque accidat, experiantur. Haec si eminuntiata Ariouisto sint, non dubitare quin de omnibus obsidibus qui apud eum sint grauissimum supplicium sumat. (9).

Ei legationi Ariouistus respondit: Si quid ipsi a Caesare opus esset, sese ad eum uenturum fuisse; si quid elle se uelit, illum ad se uenire oportere (10).

Ariouistus ad postulata Caesaris pauca respondit, de suis uirtutibus multa praedicauit: (...) experiri uelint, se iterum paratum esse decertare; si pace uti uelint, iniquum esse de stipendio recusare (...) Quod si eum interfecerit, multis sese nobilibus principibusque populi romani gratum esse facturum (11).

César se ha apartado del modelo ciceroniano por las siguientes razones: según las reglas anteriormente dadas $y$, puesto que todos estos párrafos dependen de verbos en pasado (respondit, locutus est, respondit y praedicauit, respectivamente), las formas utilizadas debieron haber sido éstas: en el primer ejemplo, el período dentur, satis faciantesse facturum está por darentur, satis facerent-esse facturum; en el segundo, los períodos edere-facta sit, sit-esse faciandum y enuntiata sint-dubitare corresponden, en ese mismo orden, a edere-facta esset, esset-esse faciendum, y enuntiata essentdubitare; en el tercero, el período uelit-oportere debió haber sido uellet-oportere y, en el cuarto, en lugar de uelint-paratum esse y de interfecerit- esse facturum, debió haber escrito uellent-paratum esse $\mathrm{e}$ interfecissent-esse facturum.

Sólo me resta decir que, pese a que para el presente trabajo no han sido tomados en cuenta todos los discursos indirectos del Bellum Gallicum, los ejemplos dados han sido cuidadosamente seleccionados, a tal extremo que se hacen representativos de lo expuesto.

\section{NOTAS}

(1) C. Iulius Caesar, Bellum Gallicum, 1,31.

(2) Ibid., I, 20.

(3) Ibid., I, 35.

(4) Ibid., I, 31.

(5) Ibid, I, 444.

(6) Ibid., V.27.

(7) Ibid., II, 14.

(8) Ibid., I, 14.

(9) Ibid., I, 31.

(10) Ibid., I, 34.

(11) Ibid., I, 44.

\section{BIBLIOGRAFIA}

Bassols de Climent, Mariano, Sintaxis latina. T. I, Madrid, Consejo Superior de Investigaciones Científicas, 1973.

C. Julio César, Comentarios de la guerra de las Galias. Madrid, Espasa-Calpe, S.A., 1976.

César, Guerre des Gaules. Paris, Les Belles Lettres, 1958. 
